Cite this article as:

Gherardini Francesco and Leali Francesco. 2017. Reciprocal Frames in Temporary Structures: An Aesthetical and Parametric Investigation. Nexus Network Journal 19(3): 741-762.

\title{
Reciprocal Frames in Temporary Structures: An Aesthetical and Parametric Investigation
}

\author{
Francesco GHERARDINI*, Francesco LEALI \\ Dipartimento di Ingegneria “'Enzo Ferrari’’, Università degli Studi di Modena e Reggio \\ Emilia,
}

Via Pietro Vivarelli 10, 41125 Modena, Italy

*corresponding author: francesco.gherardini@unimore.it

\begin{abstract}
This paper deals with the use of reciprocal frames in temporary gridshell structures, such as architectural pavilions in expositions and installations. These architectural examples can benefit from the use of short, easy to handle, generally joint-free, and repeatable "modules" in order to create particular self-supporting structures. The lightweight and interwoven grid obtained by connecting short elements according to the reciprocity principle is structurally efficient and, at the same time, aesthetically pleasing, mainly due to the resulting tessellation. The paper firstly investigates the connection between efficiency and aesthetics. The last part of the paper investigates some temporary architectural pavilions from both an aesthetical and parametric point of view. In order to deepen our understanding of these structures, they are re-modelled according to a bottom-up approach by means of a constraint-based parametric CAD modeller. In this way, a reciprocal frame can be explored and modified by the parametric arrangement of its generative elements, which, like a natural organism, grows in self-generating forms.
\end{abstract}

\section{Keywords}

Reciprocal Frame, Shell structure, Parametric modelling, Architectural pavilions, Tessellation, Aesthetics, Natural form. 


\section{Introduction}

A reciprocal frame (RF) is a three-dimensional grillage structure based on elements (beams, elongated elements or laminae) that mutually support each other. The origins and general characteristics of RFs have been examined in depth previously in this journal (Di Carlo 2008; Duvernoy 2008; Baverel and Pugnale 2014; Pugnale and Sassone 2014; Thönnissen 2014) and will not be gone into here.

Popovic Larsen (2007) defines the multiple RF grids as "reminiscent of gridshells", because of some specific characteristics. A gridshell is a structure defined by a curved (3D) surface (called "shell") and made of a grid instead of a solid surface (Douthe et al. 2006). The grid members can be continuous (spanning across the whole structure and overlapping each other at the nodes) or discrete (short beams (or rods) connecting to each other at nodes) (Naicu et al. 2014).

In order to better contextualise RFs among discrete grid member structures, and according to many authors, the hallmarks of a RF structure are:

1) it is formed by expanding and adding single RF units to the perimeter of the single unit to form a grid structure (Popovic Larsen 2007);

2) each element must work, simultaneously, both as support and supporter of other ones, without any clear structural hierarchy (Pugnale et al. 2011);

3 ) its elements support one another along their span and never at the extremities (Baverel and Pugnale 2014);

4) the length of each element is shorter than the distance to be spanned by the whole structure (Pugnale et al. 2011);

5) its elements are generally joined using friction, notching, nailing or tying (Song et al. 2013); sometimes, in larger structures, mechanical joints such as scaffolding swivel clamps are used (Sénéchal et al. 2011).

The inherent nature of RFs make them suitable for temporary architecture, such as pavilions in exhibitions and expositions. On one hand, their construction principles lead to their main advantages in manufacturing, handling, shipping, assembly and disassembly, due to the use of short - and generally lightweight - elements. On the other hand, the geometric patterns originated by RF unit arrangements, which resemble natural structures, lead to impressive forms.

Although RFs present some specific features, most of the considerations proposed here concerning aesthetics, natural form, tessellation, and temporary use can be further extended to other short beam grids, as in the case of space grids with elements connecting at their ends by means of pin joints, fasteners or fixings.

To consider all of these aims, the paper is structured as follows. In the first section, "Behind Reciprocal Frames: Structure and Aesthetics", we investigate the relationship between structural geometric forms and aesthetics. In the second section, "Analysis of Reciprocal Frames", we propose a bottom-up modelling approach for developing a "design exploration" of four small pavilions, chosen as case studies for their specific features. These structures will be partially re-modelled according to the proposed approach in order to parametrically investigate their "growth", similar to a natural organism. A brief discussion concludes the paper. 


\section{Behind Reciprocal Frames: Structure and Aesthetics}

RFs embody an interesting and close relationship between their functionality (as structures and, particularly temporary ones) and aesthetics (as architecture). Their structural language becomes an aesthetical language, mainly due to the common use of mathematical language, which RFs share with other structures we can find in Nature. This may suggest why we find them beautiful. In order to investigate this last aspect, in the last part of this section we face the themes of aesthetics, natural forms, and tessellations, all strictly connected by the use of mathematics.

\section{Aesthetics: Structure vs Architecture}

In the functional decomposition of an architecture, some main "blocks" can be distinguished based on their functions within the whole, in particular the building envelope and the loadbearing structure. Hegger et al. (2006) underline the trend in contemporary architecture in detaching the building envelope (or external skin) from the structure of the building (or skeleton): the first works to separate, or enclose, the internal space and generally defines the exterior architecture appearance, while the second assures the loadbearing functions. The surface envelope plays a dominant role in the perception of architecture (Schittich 2006) because it is what people see and touch, as if the "image" of the building is more important than the building itself. For its role, the building envelope can also be designated as a façade, even if this term referred, originally, only to the face (from the Latin word "facies") of the building, which is the side containing the entrance.

Past and recent architecture presents many examples of "envelopes", intended as both whole surfaces and decorations acting as something applied or added on to a structure, sometimes with the explicit function of concealing the structure itself. Examples of envelopes include the use of marble veneers in buildings from the Antiquity through the Renaissance and beyond; the tiles and stucco works of Islamic architecture, and the impressive 3D ornaments called muqarnas (Schittich 2006, Gherardini and Leali 2016); and the panels and sheets of glass, mirror, ceramics, and metals used as covering façades over structures in recent architecture.

On the other hand, there are many examples of architecture that establish a new relationship between façades and structures. Nina Rappaport (2006: 95) talks about "deep decoration", which she defines a decoration that is "both below and in the surface" and that "blurs the line between what is structural and what is decorative, and results in a third thing". This definition comprises RFs and grid-shells, in which the structure acts as a generator of form. As a result, the constructive elements have the double function of being supporting and decorative elements, acting as a "structural skin".

In particular, Rappaport (2006) underlines two aspects of "deep decoration": the first is the use of repetitive geometric elements (repetitive arrays) as space structures, since they envelop space and grow into forms that are self-generating. 
The second is the emphasis on the exoskeleton, because - in this orientation - the structure doubles as ornament.

However, Rappaport (2006: 96) warns that "just because a structure is exposed does not mean it is decorative". We must therefore ask what is the boundary between a structure and an architecture?

When interviewed about structures, Waclaw Zalewski (Allen and Zalewski 2009: 613) states "such so-called architectural effects of structures are often the results of engineering motivations of efficiencies in material or process, combined with opportunities to show how a structure works". Accordingly, the aesthetic value of a structure may depend on its shape and/or the shapes of the elements it is made of, on the interaction of different building materials or on the alternation between closed and open zones (Schittich 2006). More to this last point, Robert Le Ricolais said that "the structure is composed of holes, all different in dimension and distribution, but with an unmistakable purpose in their occurrence. So we arrive at an apparently paradoxical conclusion, that the art of structure is how and where to put holes" (quoted in Bryan and Sauer, 1973: 88).

More specifically on RFs, Pizzigoni (2009) states that the beauty in architecture is associated with statics, materials and the "internal life" behind the architecture itself. In particular, RFs offer beautiful new forms and compositions, in which the joints and the interweaving of structural elements emphasize the evocative and timeless image of these systems. In synthesis, he observes that the more interesting proposals from contemporary architecture based on reciprocity base their "image" on the evocative power implicitly contained in this construction principle itself. Accordingly, Popovic Larsen (2007) proposes to change the terms when speaking about RFs: they should not be addressed as "structures" but, more appropriately, as "architecture".

The absence of hierarchy in the structure of RFs, where all members share an equal status, supports the development of free and aesthetical forms, without particular constraints. In this way, the surface pattern and the internal structure grow together, creating organic patterns that are both functional and decorative. This growth approach in structures resembles the growth approach in nature, both generating "a structure with an underlying coherence from the whole to the fragmentary assemblage" (Rappaport 2006: 97). Another design feature in RFs is the use of efficiently dimensioned elements, without redundancy, in order to develop light-weight architecture. Tony Robbin, when talking about reciprocal hybrid systems, even those as simple as an Indian tepee, states that their use "constitutes a new constructive paradigm of resistance similar to that which exists in living organisms. The overloading of a structure is not only a waste of material but can be very dangerous" (1996, cited also in Di Carlo 2008: 28). Both these last two considerations touch on the idea that RFs are similar to natural organisms, where beauty and functionality are based on an intrinsic equilibrium. This leads to a further examination of architecture, natural forms and tessellation. 
Biomimicry is a universally recognized principle for efficiency and functionality, but it does not mean that it is true also for aesthetics, as proved by many controversial examples of architecture inspired by natural forms.

About structures and Nature, Waclaw Zalewski states:

Structures are not art, they exist for a purpose, to satisfy human need. But they may still be elegant or even beautiful. Not because their shape is literally like a form of Nature - our criteria for beauty in flowers are not the same as our criteria for structures. We can't make structures beautiful by copying natural forms, by making them look like flowers or trees or bones. All these forms are at scales that are too small to translate directly unto structures of the size that we need. Structures must find their own natural forms, the ones that arise from funicular polygon, the bending moment diagram, the internal flow of forces in structural members (Allen and Zalewski 2009: 613).

While imitating natural forms is not the access key to the aesthetics of structures, it is still true that the human eye can innately recognize in architectural structures, including RFs, something "aesthetical". We believe that the fascinating astonishment accompanying the view of some structures lies in two features: the use of repetition as 3D shaped mosaics, in regular or even irregular ways (as an "ordered disorder"), and the sensation of "natural growth" expressed by these structures. So, synthetically, there is a strict relationship between the origin of aesthetics in such structures and their mathematics, according to other authors.

Song et al. (2013) compare RF structures to bird nests in nature, which are built from discrete simple elements. RFs have a modular structure composed with simple rods that "nicely form self-similar and highly symmetric patterns, capable of creating a vast architectural space as a narrative and aesthetic expression of building" (Song et al. 2013: 1). They also state that RF-structures built with one or more similar fans have an intrinsic beauty derived from their inherently self-similar and highly symmetric patterns.

The innovative value of RFs and their suggestion of form is connected to "the principles, upon which the equilibrium of the reciprocal structure is founded, (that) seem, in fact, to encounter very different subjects, from geometry to biology" (Pizzigoni 2009: 1905).

Moreover, the strict connection between tessellation patterns and fan arrangements in RF structures is one of the main reasons for their beauty. Song et al. (2013: 4-5) propose the duality between a RF tessellation with rotationally-symmetrical fans and an edge-toedge tiling by congruent regular polygons. Faces and edges in a plane uniform tiling (Fig. 1 (top row)) are replaced by RF fans and their connections (Fig. 1 (middle row)): every fan is the vertex of a polygonal grid (in blue line), whose dual tiling (in red dashed line) is developed by connecting the centroid of every polygon (Fig. 1 (bottom row)).

Beside structural performance, Malek and Williams (2013) investigate the "new aesthetical possibilities" offered by the use of Cairo (pentagonal) and hexagonal tiling for the design of gridshells. Among the dual semi-regular tilings, a Cairo tiling 


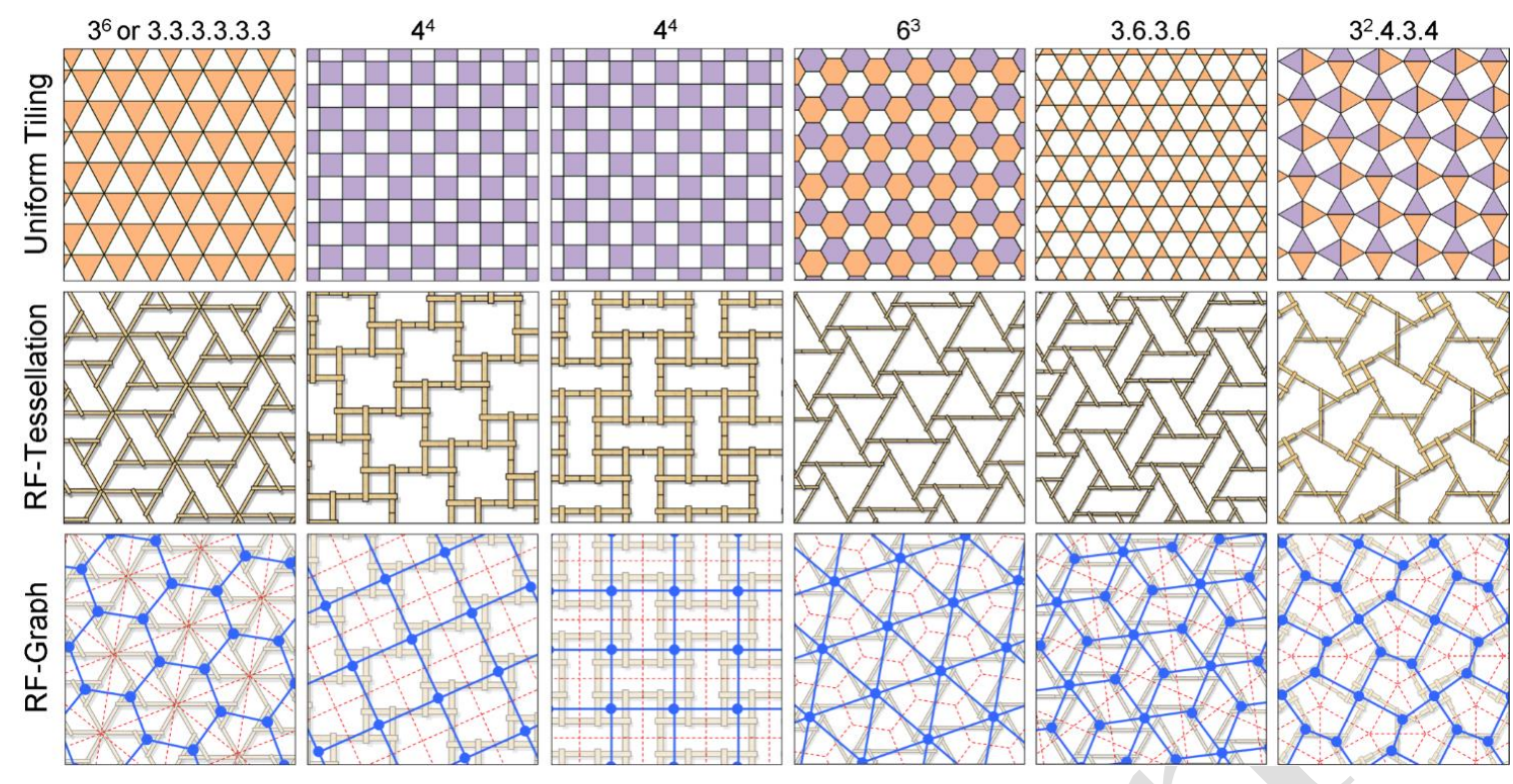

Fig. 1 Duality between RF tessellation (middle row) and uniform tiling (top row) (Reproduced

by kind permission of Peng Song and Chi-Wing Fu. Source:

http://www.cse.cuhk.edu.hk/ cwfu/papers/recipframe/index.htm)

represents the dual tiling of a semi-regular tiling of squares and equilateral triangles (see the red dashed line in Fig. 1 (bottom of the last column)). Popovic Larsen (2007: 2) identifies that, because of the geometrical characteristics of RFs, "the most appropriate forms of buildings (in plan) using the RF are circular, elliptical and regular polygonal. As a result, most of the buildings constructed using the RF have regular polygonal or circular plans. In the case of regular plan forms, all RF members are identical, which gives the possibility of modular RF construction". Again, Rappaport (2006: 97) observes that "the pattern becomes decoration when it engages in the act of defining a spatial affect".

In conclusion, we can state that the key point in the development of an "aesthetical structure" is not imitating Nature but understanding Nature and the rules derived by the physics underlying Natural principles and, therefore, their mathematics. The mathematics of natural forms offers an objective support for facing some of the open issues in the aesthetical development and construction of RFs. In this way, using the words of Maurits Cornelis Escher "for me it remains an open question whether [this work] pertains to the realm of mathematics or to that of art" (quoted in Emmer 2003: 144-145).

\section{Analysis of Reciprocal Frames}

In this Section we propose an investigation of some temporary architectural pavilions from both an aesthetical and parametric point of view.

First, we propose a bottom-up approach by means of a constraint-based parametric $\mathrm{CAD}$ modeller, able to explore and better analyse the influence of design parameters locally or globally on the RF morphology.

Then, we present four pavilions designed as temporary RFs, whose designs are further explored by re-modelling part of their structures according to the proposed 
bottom-up approach. The description and the analysis of each of the four RFs reflect the focal aspects previously discussed about the design of a RF, based on 1) the definition of the single units to be assembled and 2) the study of their composition, other than their jointing system. In this way, we analyse and modify the parametric arrangement of their generative elements, similar to natural organisms, which grow in self-generating forms.

\section{Bottom-up Modelling Approach}

The proposed bottom-up approach is able to produce modifications to the RF structure by modifying the values of the fan design parameters, as style (orientation), engagement length, eccentricity, end dispositions, and number of elements, in order to understand how they influence the RF morphology.

This idea originated from the analysis of natural shapes, which grow up by means of geometric elements to generate a surface structure. In this approach, the form generator is the fan and its relationships with the surrounding fans that, as a corallite in a coral colony, grows with a predetermined spatial order, but adapting to the surrounding environment.

In the proposed bottom-up approach, we start from the fan design parameters of the chosen RF: each element is modelled and assembled in the corresponding fan. However, each parameter can potentially vary within a fixed range or between discrete options, so it can determine a modification in the final morphology of the surface. The aim is not to tessellate (or to fill with fans) a predetermined surface, but to understand or, better, to explore, how the structure will grow on the basis of the design parameters.

With these aims, we employ a constraint-based parametric 3D CAD program (SolidWorks by Dassault Systemes) and we develop a CAD application (a macro) in Visual Basic. The macro is able to replicate the fan in n-configurations, by modifying one or more design parameters within their ranges. They can be modified one at a time, or by combining their levels as in a Design of Experiments.

The sequence of steps in the proposed bottom-up approach are:

1) Definition of the single element for parametric modelling and, then, the fan design (number of elements, its shape, definition of design parameters, and definition of parameter ranges),

2) Identification of variability ranges for each design parameter,

3) Launch of the macro, which recalls the design parameters, assigns them values within the established ranges, and generates the fan,

4) Setting two growth directions for the surface and the connecting points on the fan,

5) Adding new fans along the growth directions,

6) Assessment of the spatial disposition by exploring how the structure will grow and iteratively modify it by acting on a single or multiple design parameters,

7) At this point, or after iterative steps, the designer can continue to add other underconstrained fans along the other direction, with some degree of freedom, 
in order to fill the structure. By manually acting on these fans, the structure can be completed according with the trends along the two main growth directions.

\section{Parametric Investigation of Temporary RF Pavilions}

In our analysis we will focus on surface-like structures, using the case of small temporary pavilions built for expositions and exhibitions. They are mainly selected and analysed for their morphology and aesthetics. The awareness of their temporary nature leads to the choice of unusual materials for architecture, mainly because the lightness of weight is preferred to durability. The pavilions have been designed by architects, academics, and design/architecture students. Each selected pavilion differs from the others in design parameters and specific features, which are described in Table 1.

Among the design parameters listed in the first column of Table 1, the following ones directly influence the morphology of the fan and, therefore, of the whole RF: Element type, Number of fan elements (n), Style (or orientation), Engagement length ( $\lambda$, as a portion of the element length L), Eccentricity (e, the shortest distance between the axes of connected elements), End disposition (the element end may be above or below its supporting element). Each selected pavilion is described and then analysed by remodelling its fans and structure, in order to investigate what effect derives by varying one or more of these design parameters, which are the main contributors to their morphology.

1) Name: Forest Park Pavilion (scaled prototype)

Author: Shigeru Ban and Cecil Balmond of Arup, London

Location: St. Louis, Missouri, USA

Year: 2007

Material: Compressed bamboo laminate

Source: http://www.shigerubanarchitects.com/works/2002_bamboo-roof/index.html and

http://www.balmondstudio.com/work/forest-park-pavilion.php

Brief description: The fans consist of four bamboo boards in a spiralling (clockwise) pinwheel connection. Each fan shares a board with each of the adjacent four fans. The resulting RF tessellation consists of a small square surrounded by big squares, which corresponds to the dual of a $4^{4}$ tiling (see the shadow in Fig. 2b). Each board presents four holes (for fasteners) and is pre-cut and drilled before being shipped to the site. The shell structure presents a concave and convex surface. These changes in curvature result from different end dispositions of the elements in each fan and - moreover - the use of non-uniform spacers when joining the elements themselves, as in (Danz 2014). Five bundled steel poles support the structure (Fig. 2a). The pre-assembled grid shell was hoisted in the air by crane as the steel pole supports were secured underneath.

The engagement length $\lambda$ and the end disposition of the elements (within the fan or among different fans) are the main parameters for determining and changing the curvature of the RF. The engagement length determines the height of the fan: Fig. 3a (left) shows a fan with $\lambda=\mathrm{L} / 3$, which presents a total height $\mathrm{H}>0$ and positive end dispositions. Using the same $\lambda$, but changing the position of one of the 
Table 1 Parametric investigation of four temporary RF pavilions

\begin{tabular}{|c|c|c|c|c|}
\hline & $\begin{array}{c}\text { Forest Park } \\
\text { Pavilion (scaled } \\
\text { prototype) }\end{array}$ & $\begin{array}{c}\text { Proposal for the } \\
\text { Italian Pavilion } \\
\text { at Expo } 2010 \\
\end{array}$ & $\begin{array}{c}\text { Arched } \\
\text { Reciprocal } \\
\text { Frame } \\
\end{array}$ & WikiVault \\
\hline Element type & $\begin{array}{l}\text { Elongated } \\
\text { element (board, as } \\
\text { called by Shigeru } \\
\text { Ban) }\end{array}$ & $\begin{array}{l}\text { Double S-shaped } \\
\text { beam }\end{array}$ & $\begin{array}{l}\text { Thin elongated } \\
\text { straight bars }\end{array}$ & $\begin{array}{l}\text { V-shaped planar } \\
\text { elements (similar } \\
\text { to folded plate) }\end{array}$ \\
\hline $\begin{array}{l}\text { Number of fan } \\
\text { elements }\end{array}$ & $\begin{array}{l}4 \quad \text { identical } \\
\text { members }\end{array}$ & $\begin{array}{l}4 \quad \text { identical } \\
\text { members }\end{array}$ & $\begin{array}{l}3 \quad \text { identical } \\
\text { members }\end{array}$ & $\begin{array}{l}4 \text { identical } \\
\text { members (except } \\
\text { for the fans in the } \\
\text { RF extremities) }\end{array}$ \\
\hline Style (orientation) & Right & $\begin{array}{l}\text { Right and left } \\
\text { assembled } \\
\text { together }\end{array}$ & $\begin{array}{l}\text { Right and left } \\
\text { assembled } \\
\text { together }\end{array}$ & Right \\
\hline $\begin{array}{l}\text { Engagement } \\
\text { length }\end{array}$ & $\lambda=\mathrm{L} / 3$ & $\lambda=\mathrm{L} / 3$ & $\lambda=\mathrm{L} / 3$ & $\lambda=\mathrm{L} / 2$ \\
\hline Eccentricity & $\begin{array}{l}\text { Variable, equal or } \\
\text { major (due to the } \\
\text { joints) of bar } \\
\text { thickness }\end{array}$ & $\begin{array}{l}\text { Equal to bar } \\
\text { height }\end{array}$ & $\begin{array}{l}2 / 5 \text { of bar height } \\
\text { by notching }\end{array}$ & $\begin{array}{l}\text { Variable along } \\
\text { curvature, } \\
\text { globally } 1 / 4 \text { of } \\
\text { element height }\end{array}$ \\
\hline End disposition & $\begin{array}{l}\text { Both positive and } \\
\text { negative }\end{array}$ & Positiv & Positive & Positive \\
\hline $\begin{array}{l}\text { Connection } \\
\text { between fan }\end{array}$ & $\begin{array}{l}\text { Sharing a } \\
\text { common bar }\end{array}$ & $\begin{array}{l}\text { Both sharing a } \\
\text { bar and T-join } \\
\text { contact }\end{array}$ & $\begin{array}{l}\text { Both sharing a bar } \\
\text { and } \mathrm{T} \text {-join contact }\end{array}$ & $\mathrm{T}$-join contact \\
\hline $\begin{array}{l}\text { RF tessellation } \\
\text { (dual tiling) }\end{array}$ & $\begin{array}{l}\text { Regular square } \\
\left(4^{4}\right)\end{array}$ & $\begin{array}{l}\text { Regular square } \\
\left(4^{4}\right)\end{array}$ & $\begin{array}{l}\text { Based on regular } \\
\text { hexagon }\left(3^{6}\right)\end{array}$ & $\begin{array}{l}\text { Regular square } \\
\left(4^{4}\right)\end{array}$ \\
\hline Joining & $\begin{array}{l}\text { Mechanical } \\
\text { fastening (as } \\
\text { bolts) with non- } \\
\text { uniform element } \\
\text { spacers }\end{array}$ & Friction & Notching & $\begin{array}{l}\text { Interlocking, } \\
\text { mortise and tenon } \\
\text { joint }\end{array}$ \\
\hline $\begin{array}{l}\text { Surface } \\
\text { morphology }\end{array}$ & $\begin{array}{l}\text { Undulating } \\
\text { (concave and } \\
\text { convex) surface, } \\
\text { resulting from the } \\
\text { end disposition of } \\
\text { fan elements and } \\
\text { the eccentricity }\end{array}$ & $\begin{array}{l}\text { Doubly curved } \\
\text { surface, obtained } \\
\text { by the beam } \\
\text { shape }\end{array}$ & $\begin{array}{l}\text { Doubly curved } \\
\text { surface: the main } \\
\text { one corresponds } \\
\text { to the arched vault }\end{array}$ & $\begin{array}{l}\text { Doubly curved } \\
\text { surface, resulting } \\
\text { from the inner } \\
\text { angle of the V- } \\
\text { shaped panel and } \\
\text { the inclination of } \\
\text { each element end }\end{array}$ \\
\hline
\end{tabular}

extremities in the fan (i.e. all the end dispositions are positive but one), the fan is flat as in Fig. 3a (right), where two element extremities are both under the same element. The consequences are respectively the RFs shown in the upper part of Fig. 3b. An alternative design is shown in the lower part of Fig. 3b, where the end dispositions within the fan are all positive, but the end disposition of one element between different fans is negative.

Moreover, Fig. 3c shows a RF obtained by the combination of fans with different end dispositions, where the RF curvature varies from concavity to convexity. 


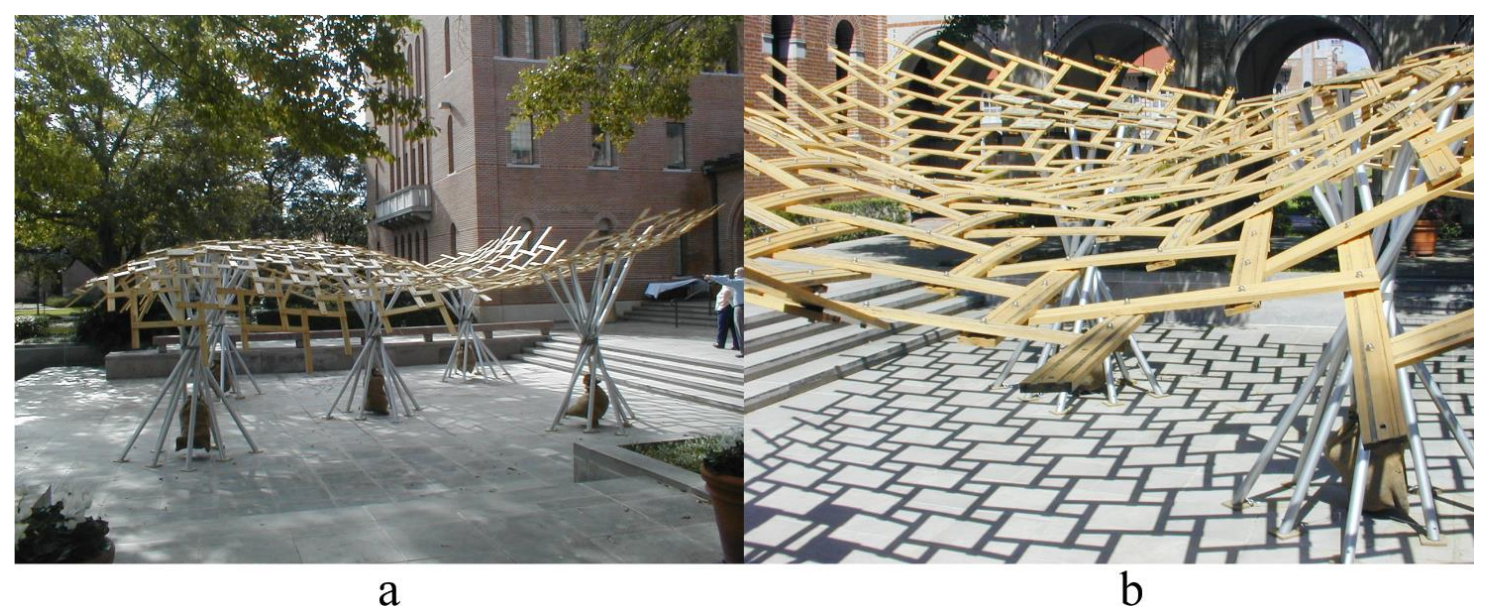

Fig. 2 Forest Park Pavilion: a. view of the whole structure (Reproduced by kind permission of Shigeru Ban Architects. Source: http://www.shigerubanarchitects.com/works/2002_bambooroof/index.html); b detail on the irregular disposition of element ends in a fan (Reproduced by kind permission of Cecil Balmond. Source:

http://balmondstudio.tumblr.com/image/99042621238)

As a general principle, the RF curvature is not univocally obtained, but some combinations of values of the engagement length $\lambda$ and the end dispositions may lead to equal resulting surfaces.

Independently from its curvature, the surface presents a regular square tessellation $\left(4^{4}\right)$.

By modifying the engagement length $\lambda$, the tessellation type does not vary, but the dimensions of the surface elements are scaled as in Fig. 4 , where $\lambda$ ranges from $L / 3$ to $\mathrm{L} / 2$.

2) Name: Proposal for the Italian Pavilion at the Expo 2010 in Shanghai, China Author: Attilio Pizzigoni

Location: Prototype

Year: 2010

Material: Bamboo laminate beam (other prototype: fibre-reinforced high performance concrete)

Source: (Pizzigoni 2009)

Brief description: The RF pavilion was designed for the competition announced in 2008 by the Italian Foreign Office for the construction of the Italian Pavilion at Expo 2010 in Shanghai. The structure, which has a double curvature, had to cover a square plan measuring 60 linear metres per side, without central supports as rods rest (Fig. 5). According to the sustainable aim of the exposition, the pavilion was to be disassembled at the exposition end and potentially reused, even with different function or form. With this aim, the designer focuses on the morphology of the element, according to a reciprocal construction principle, so that the shape of the element totally determines the final surface of the pavilion. The element presents a double S-shape, in order to reduce the overlap between elements without reducing the resistant section. Moreover, the S-shaped element avoids the need to incline the beam. Eighty-four beams are arranged in quadrilateral fans, both in right and left orientation, connected by sharing a bar and by $\mathrm{T}$-joint contact. This originates a RF tessellation consisting of a small square surrounded by four rectangles, which corresponds to the dual of a $4^{4}$ tiling. The beams are suitable to be (re-)composed in 


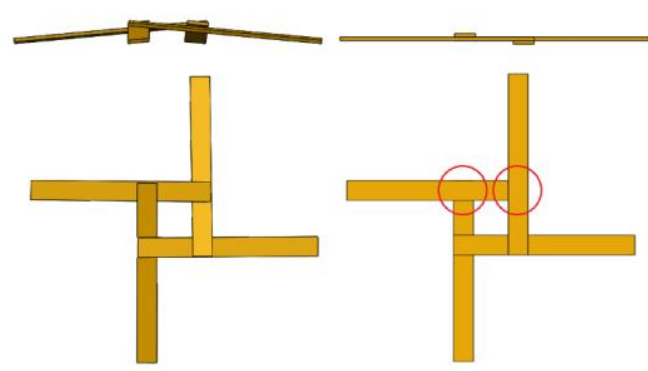

a
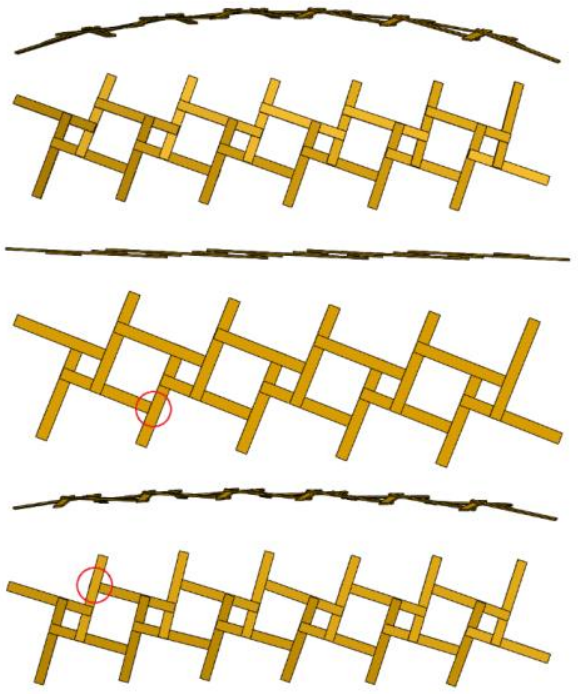

b
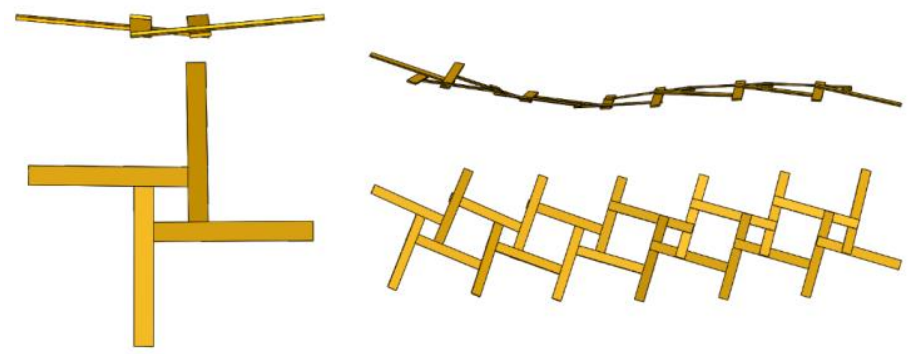

c

Fig. 3 a) Effects of the end disposition of the elements on the fan arrangement; b, c) effects of end disposition on the RF curvature

order to obtain triangular and hexagonal tessellation. The connections between elements in the fan, and between fans, are guaranteed by friction.

The morphology of the double S-shaped element is shown in Fig. 6 (top). The parameter named as $\mathrm{d}$ corresponds to the distance between the horizontal surfaces of the element and controls the curvature of the whole structure. When assembling a pair of the double $S$-shape elements, the parameter $d$ acts as the eccentricity when assembling a pair of common straight beams. Fig. 6 (bottom) shows also the different style (or orientation) of the fans used to obtain the RF tessellation as proposed by Pizzigoni.

Because of its importance in the design of the RF, by modifying the value of $d$, the whole structure changes its shape. When $d=0$, the fan and, consequently, the 

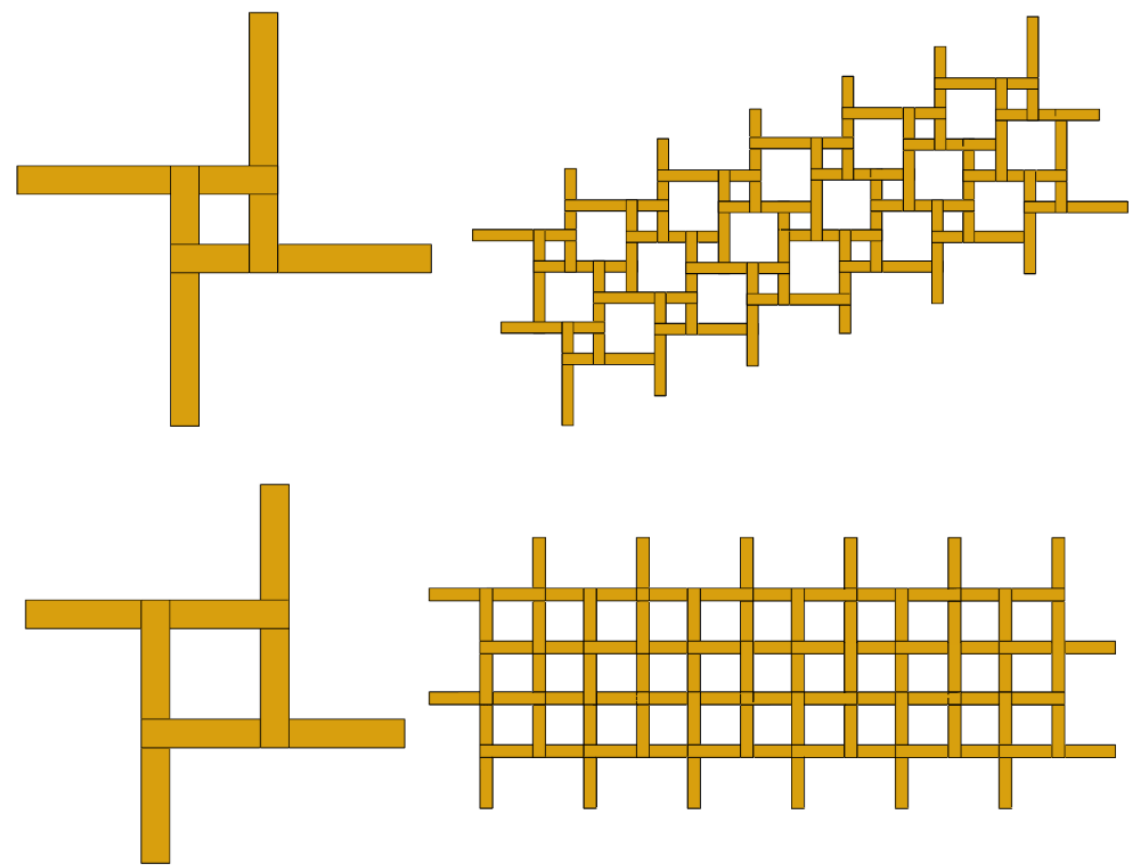

Fig. 4 Effects of the engagement length $\lambda$ on the RF pattern

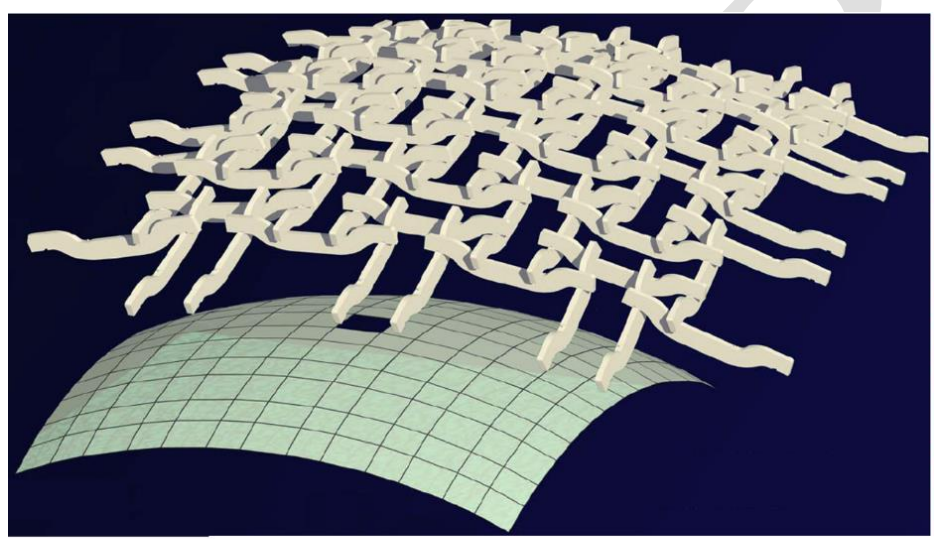

$\mathrm{a}$

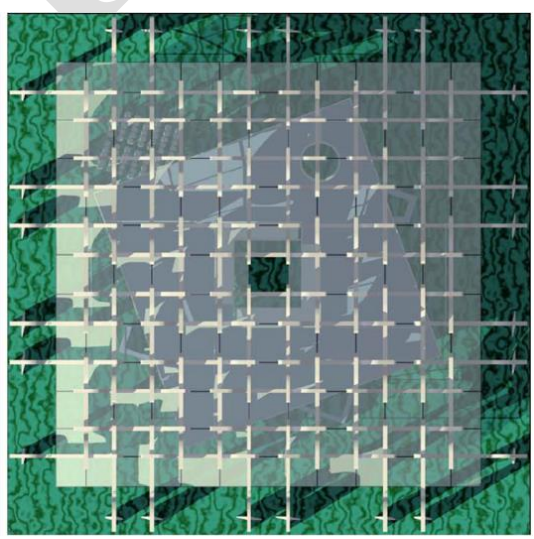

b

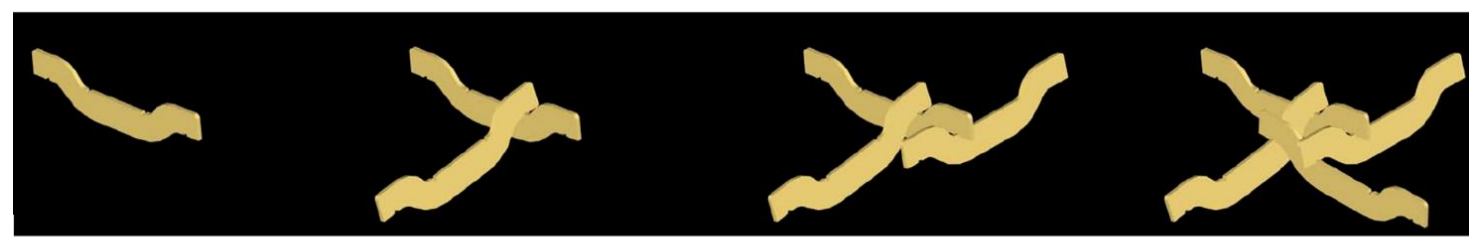

c

Fig. 5 Proposal for the Italian Pavilion at Expo 2010: a) resulting shape of the structure; b) top view and tessellation; c) fan assembly (Reproduced by kind permission of Attilio Pizzigoni.

Source: www.pizzigoni.it/leonardo\%20Eng.pdf)

whole structure are flat (Fig. 7a); in this case, the height $\mathrm{H}$ of the fan is equal to 0 . When $d>0$, the fan increases its height and, therefore, the inner surface of the whole structure curves inward (concavity, Fig. 7b), and vice-versa (d<0, convexity, Fig. 7c). 

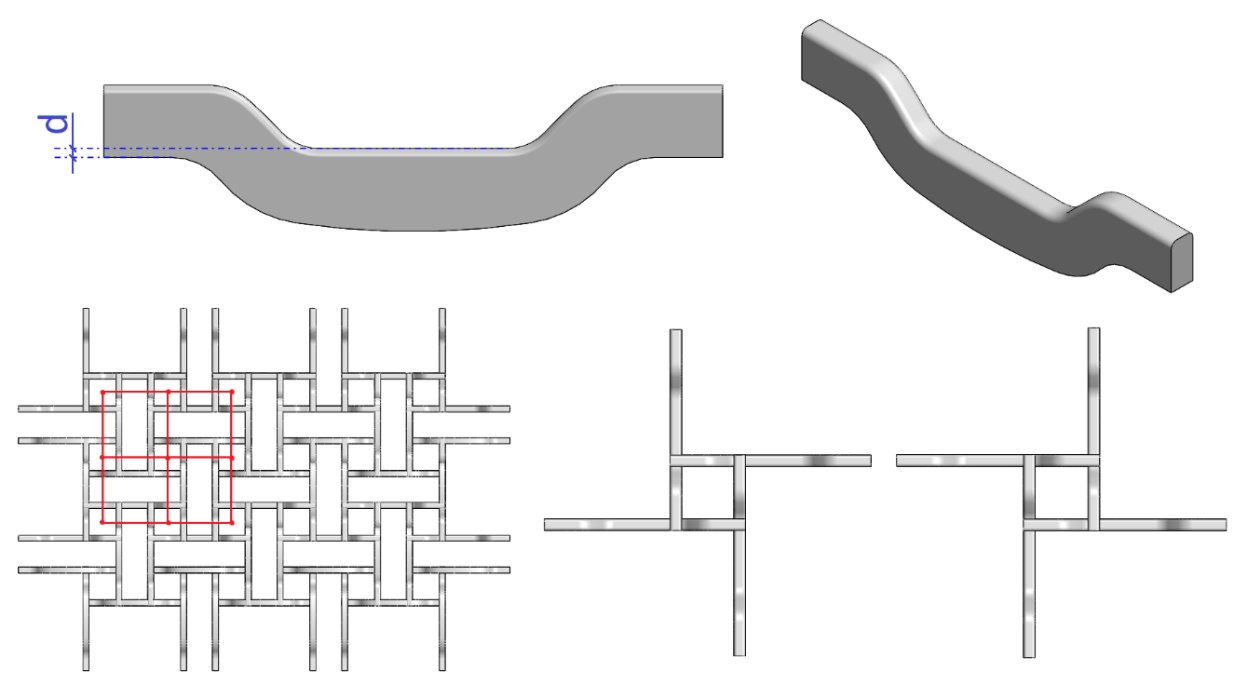

Fig. 6 Morphology of the double S-shaped element and the fan arrangements in the proposed

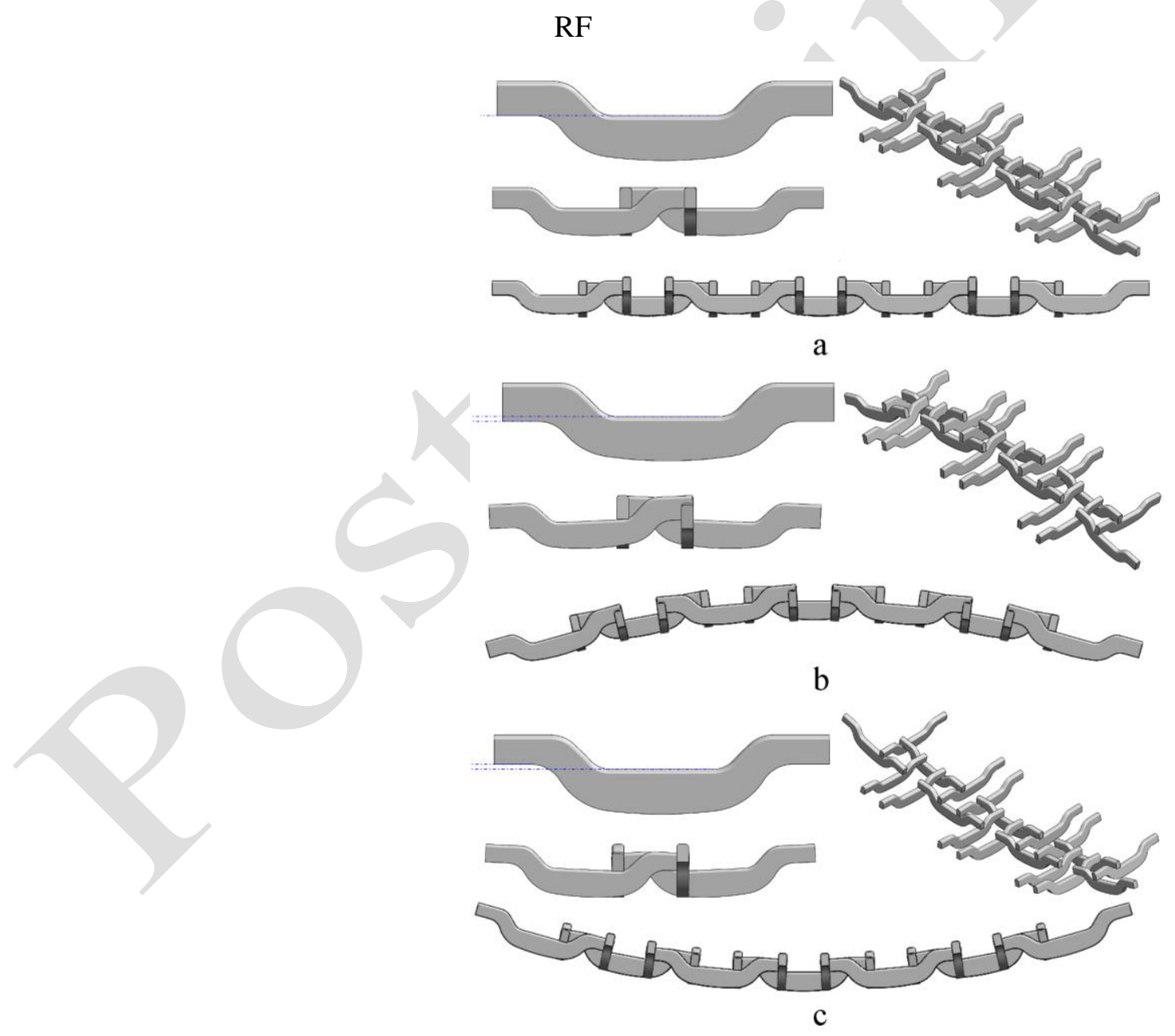

Fig. 7 a, b, c) effects of the distance d (corresponding to eccentricity) on the fan arrangement and on the RF curvature

Conversely, if $\mathrm{d}$ is fixed, all the other inner dimensions of the double S-shaped element can be modified (as its total height or its thickness). As a result, the shape of the RF surface will not vary, but the S-shaped element may be strengthened or lightened according to the structural performance to be achieved. 
Moreover, the beam elements are suitable to be arranged in fans with different numbers of elements, as shown in Fig. 8, where a triangular fan is able to produce different RF-tessellation patterns. The element shape permits to easily modify the engagement length $\lambda$.

3) Name: Arched Reciprocal Frame

Author: Matthew Marcarelli, Theodore Nicholas, and Robert Stearns

Location: PhilaU's campus lawn

Year: 2012

Material: Plywood

Source: http://www.coroflot.com/m_marcarelli/Reciprocal-Frame

Brief description: This large-scale arched RF is built by means of twenty-five elongated straight plywood bars, arranged in triangular fans. Each couple of fans, with opposite styles, shares a transversal bar (Fig. 9). The resulting RF tessellation, if further extended beyond the arch sides, will be regularly hexagonal (whose dual is a $3^{6}$ tiling). The morphological shape of the arch is obtained by simultaneously modifying the eccentricity, the notching depth and the orientation of each bar along its longitudinal axis. The resulting effect is a double curvature vault. The main curvature corresponds to the arched vault.

The notch depth is the main parameter for controlling the curvature of the arched frame. In a regular fan, the bar is symmetrical, so each bar presents four symmetrical notches, the inner ones to support other bars and the external ones to be supported. In the simplest case, all the notches have the same depth (dn, as in Fig. 10), but equivalent effects may be obtained by different notch depths. We consider a fan assembled by identical bars with height $\mathrm{Z}$, notch depth dn, eccentricity e (calculated as the distance between their axes in the bar intersecting point), notch distances from one of the bar extremity (s1 and s2), as in Fig. 10.

When the notch depth is equal to half the bar height ( $\mathrm{dn}=\mathrm{Z} / 2)$, the structure is flat (Fig. 11a). Conversely, when the notch depth is equal to $0(\mathrm{dn}=0)$, the eccentricity shown by the fan is $e=Z$ (Fig. 11b): however, this case is not suitable for a multiple fan arrangement because of the absence of notches between bars. More commonly, the notch depth ranges between $0<\mathrm{dn} \leq \mathrm{Z} / 2$, so the resulting structure for a fixed value within this range (e.g. dn=Z/4) is shown in Fig. 11c.

By keeping the ratio constant between the notch depth dn and the element height $\mathrm{Z}$, and for a fixed total length $L$ of the bar, it is possible to modify the other bar
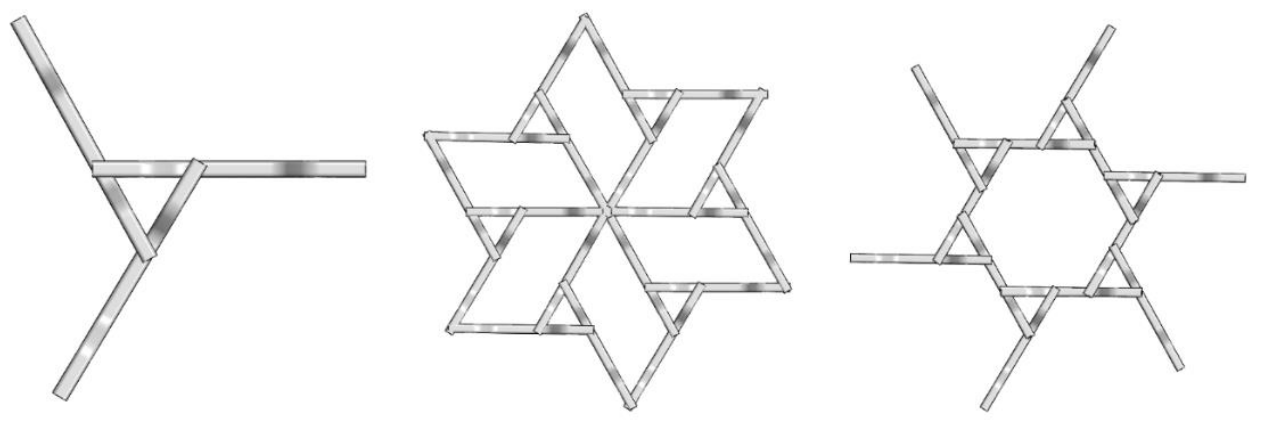

Fig. 8 A triangular fan and two of the possible related RF-tessellations 


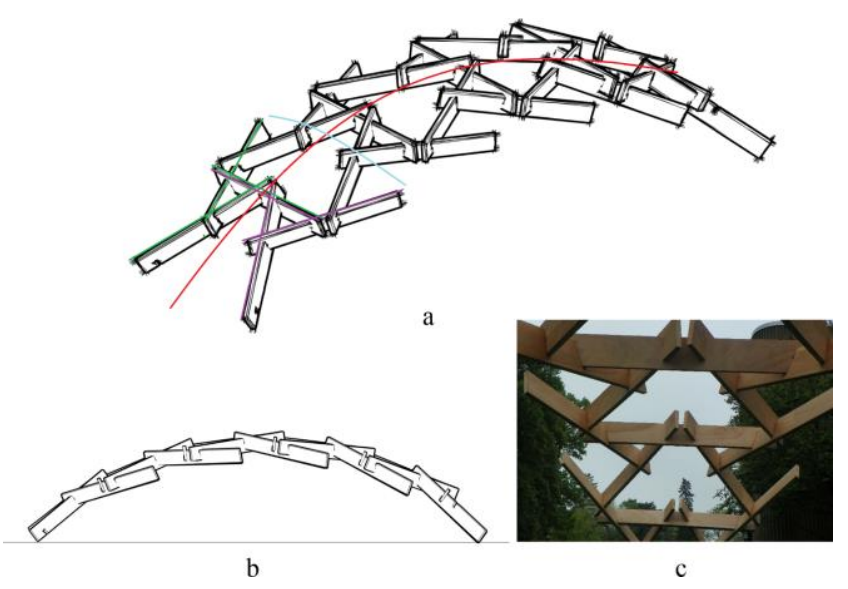

Fig. 9 Arched Reciprocal Frame: a) fans with different styles (in green and purple) and main and minor curvatures (in red and in light blue); b) side view; c) notch details. (Reproduced by kind permission of Matthew Marcarelli. Source: http://www.coroflot.com/m marcarelli/Reciprocal-Frame)

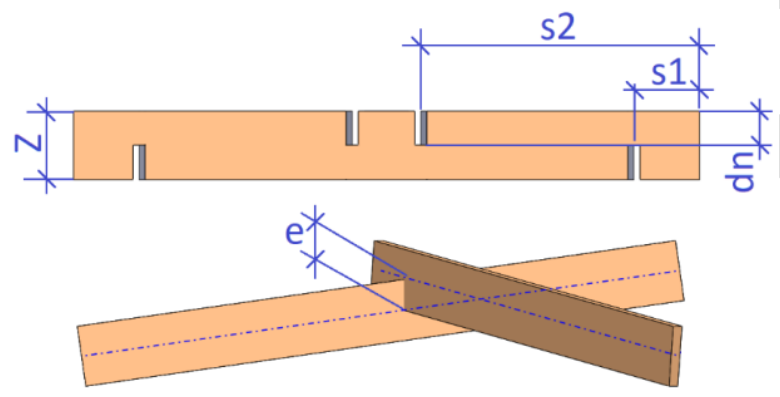

Fig. 10 Main parameters of the bar and between bars within a fan

dimensions in order to strengthen or lighten each bar, and, therefore, the whole structure, without surface shape modification.

When the notch depth is fixed, the fan - and therefore the whole RF - may be modified by acting on one (or both) of the notch distances from one of the bar extremity (s1 and s2). By varying the notch distances, the total length of the whole structure will change, so the RF is able to span increasing lengths. Fig 12 shows two different cases, in which only s1 will vary (top, $\mathrm{s} 1=\mathrm{Z}$; bottom, $\mathrm{s} 1=1,5 \mathrm{Z}$ ).

It is interesting to note that the RF surface is not univocally obtained, but some combinations of the values of the notch depth and of the notch distances can lead to identical resulting surfaces, even if they will show different fan dimensions.

4) Name: WikiVault

Author: Michael Clarke

Location: Prototype

Year: 2013

Material: Flat sheet material (cardboard in prototype, wood panel in final work)

Source: https://wewanttolearn.wordpress.com/2013/02/20/wikivault

Brief description: The prototype shows a RF made of flat sheet material, which can be efficiently assembled without the aid of formwork (Fig. 13) because the vault selfsupports as it grows in size. The flat sheet material can be easily pre-fabricated offsite and easily transported to the site. The RF consists of $77 \mathrm{~V}$-shaped planar elements, identical but for the elements at its extremities. The elements are 

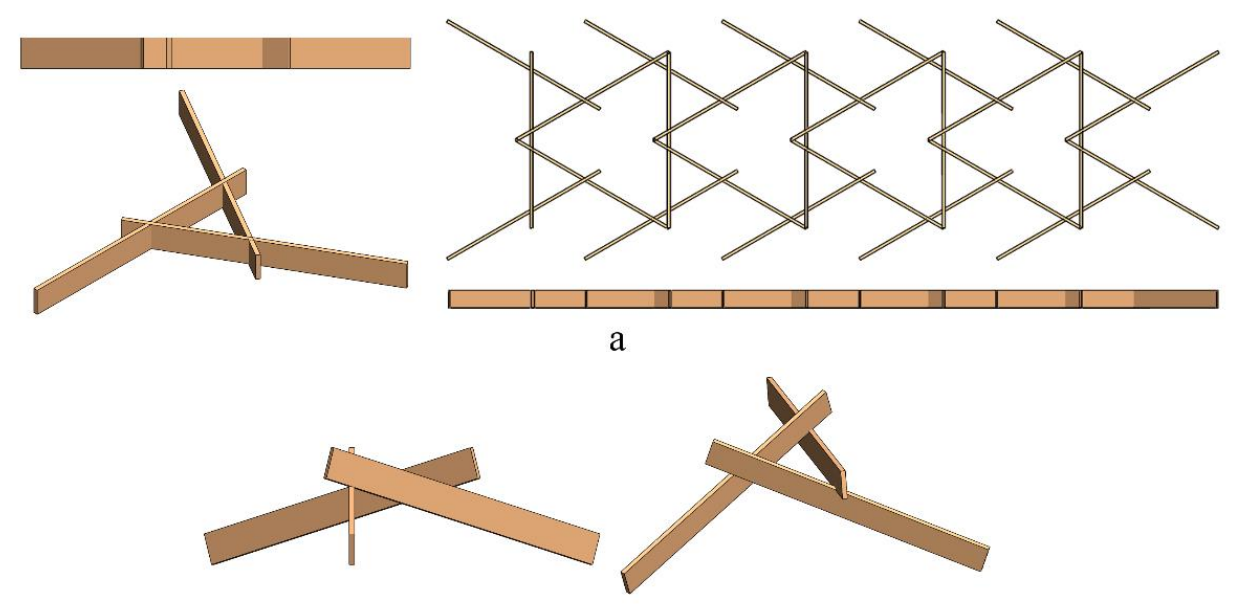

b

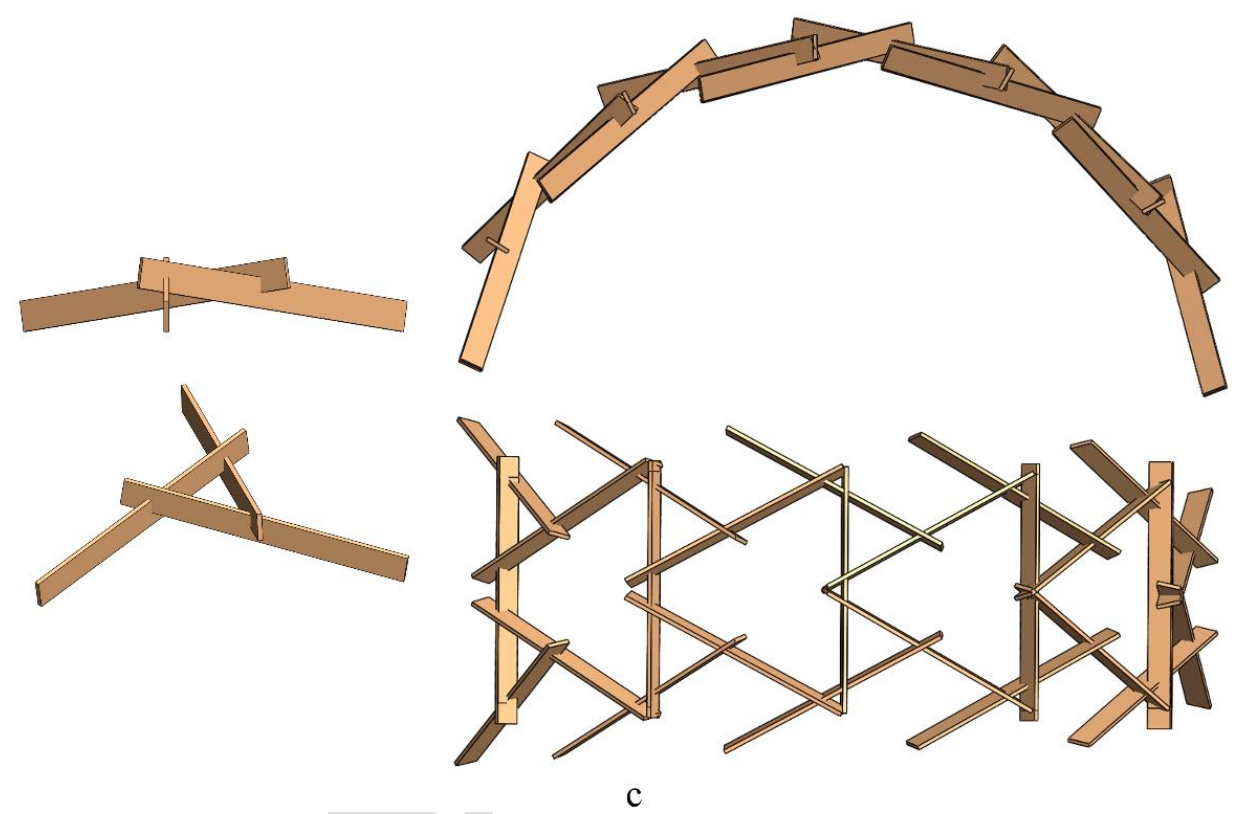

Fig. 11 a, b, c) Effects of the notch depth (dn) on the fan arrangement and on the RF curvature
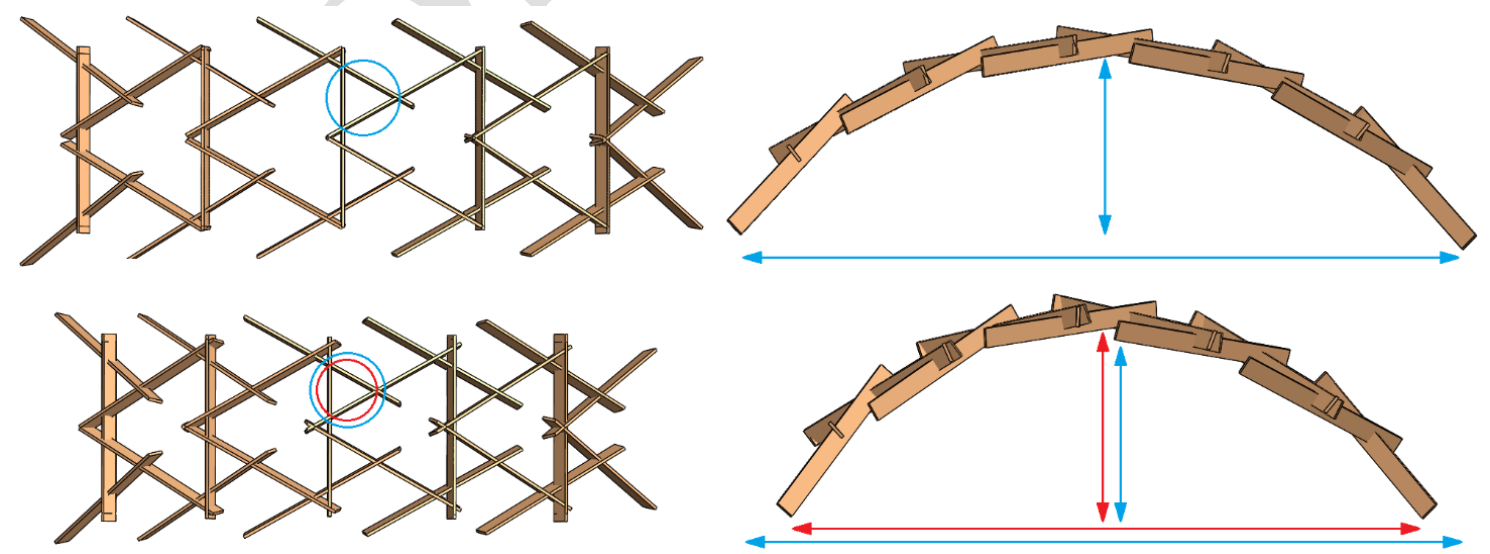

Fig. 12 Effects of the notch distance (s1) on the fan arrangement and on the RF dimensions

assembled without mechanical fixing or joints, but with notches shaped as mortises and tenons, so the elements are slotted together. Due to the engagement length equal to half the element length, the resulting RF tessellation consists of equal squares $\left(4^{4}\right.$ 


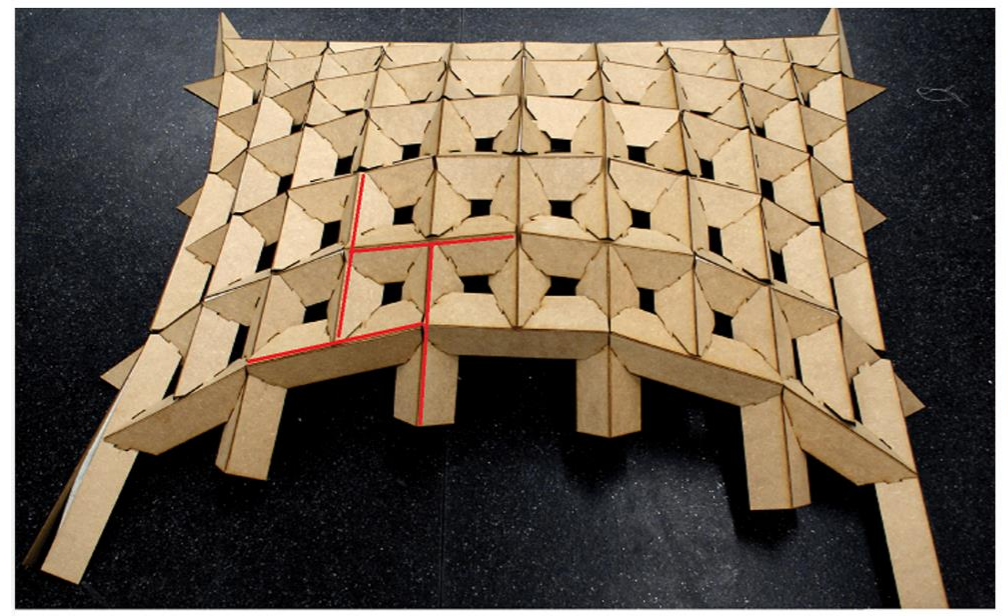

a

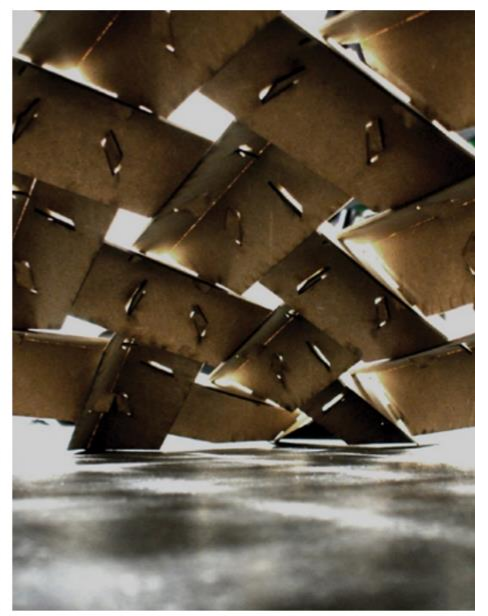

b
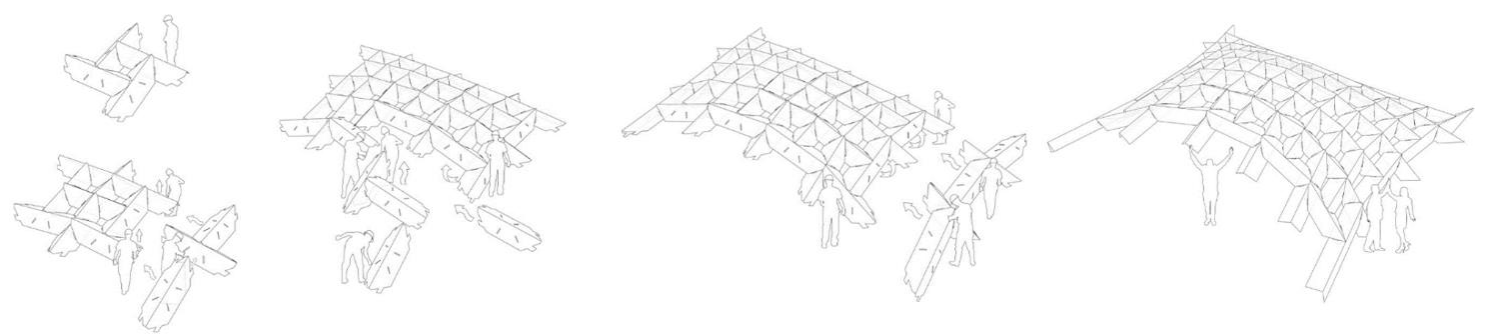

C

Fig. 13 WikiVault: a) structure and detail of its fan (in red); b) detail of the joint: mortise and tenon; c) steps of physical model assembly, from single fans to whole structure (Reproduced by kind permission of Michael Clarke. Source: https://wewanttolearn.wordpress.com/2013/02/20/wikivault)

tiling). The fan can be built also by reversing each element, with the V turned upwards, so the whole structure appears to be turned upwards, showing the mortise and tenon joints. The support elements and extremities can be modified in length and inclination. The final shape and the RF elements are inspired by Joseph Abeille's flat vault of 1699 (Fleury and Sakarovitch 2012). The doubly curved surface results from combining the inner angle of the V-shaped panel and the cutting angle at each element's end.

The V-shaped element is characterized by two design parameters: the inclination (cutting angle) of the $\mathrm{V}$-shaped element at each extremity and its inner angle, as in Fig. 14a.

For a fixed length and a fixed inner angle, the inclination (cutting angle) of the Vshaped element at each extremity is the main parameter in order to determine the RF curvature (Fig. 14b). In particular, when the angle between the inclined extremities is equal to the inner angle, the RF is flat (see the top of Fig. 14b).

Even if the RF curvature may be modified also by the inner angle, this parameter mainly controls the filling of the structure, by modifying the dimensions of the "holes" as in Fig. 14c.

Moreover, the engagement length within the fan is the main parameter in order to determine and change the surface pattern of the RF, but keeping the tessellation (Fig. 15). Further effects on the RF may be obtained by simultaneously modifying the inner angle of the V-shaped element and the inclination (cutting angle) at each element extremities. 

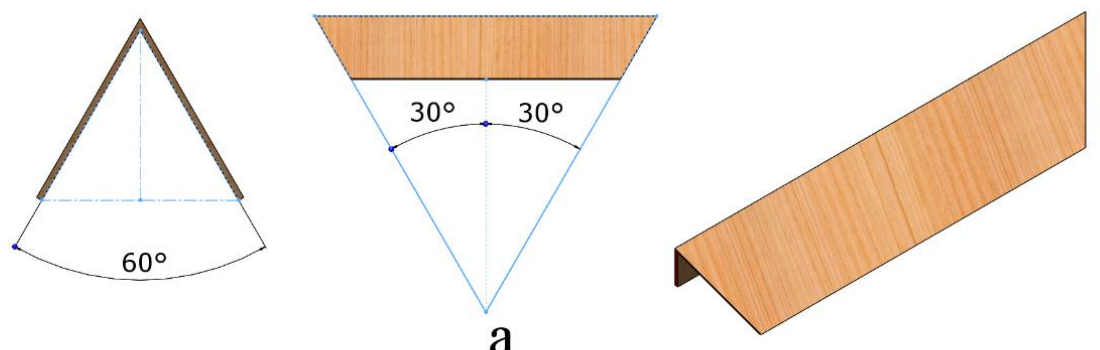

a
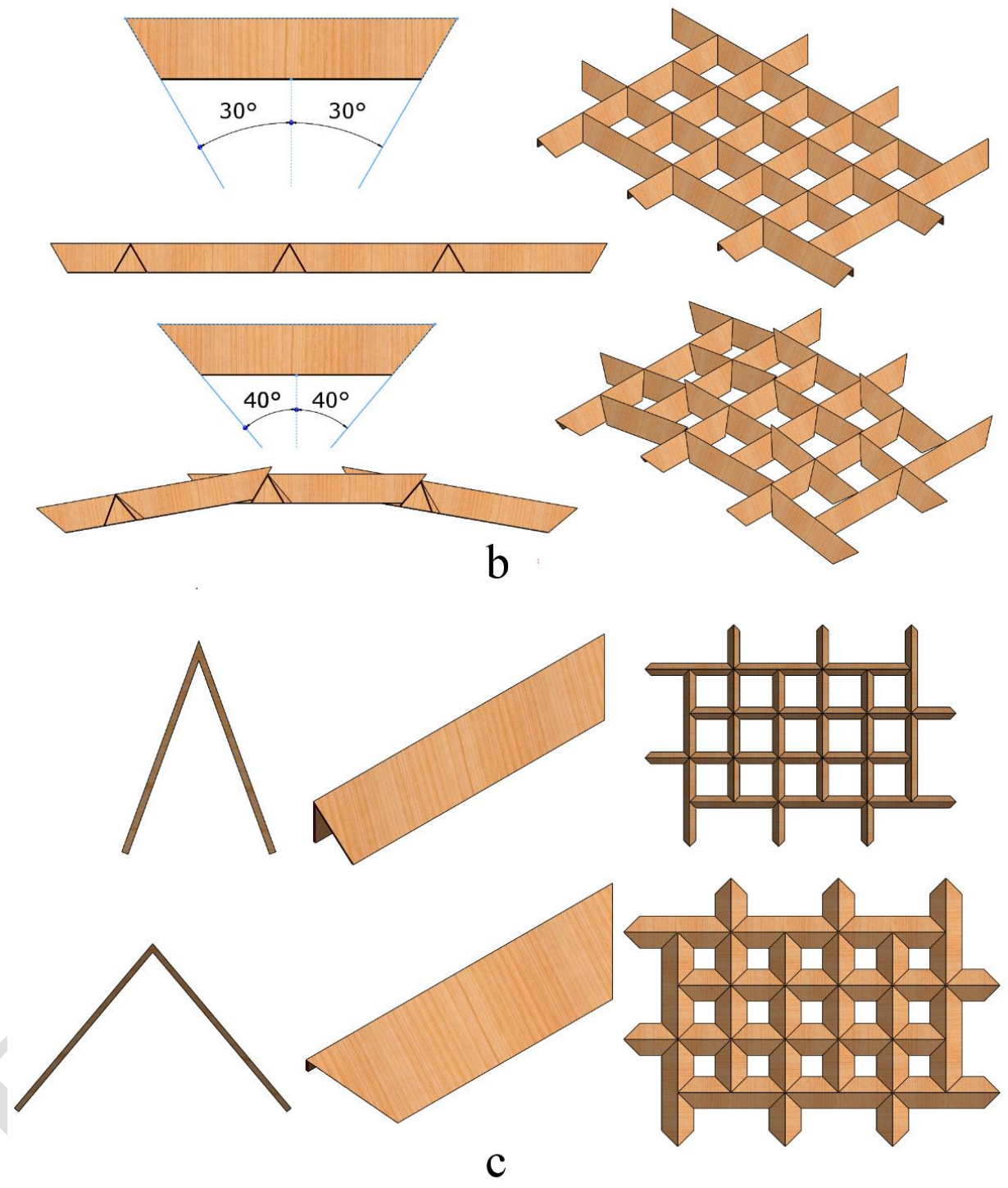

Fig. 14 a) Design parameters of the V-shaped element; b) Effects of the inclination (cutting angle) of the V-shaped element at each extremity on the RF surface in terms of curvature; c)

Effects of the inner angle on the RF surface in terms of "filling"

\section{Conclusions and Suggestion for Further Studies}

This paper deals with the use of the reciprocity principle in temporary architectural pavilions in order to assess the relationship between their geometric self-supporting structures and their aesthetics. We collected the points of views of many scholars 

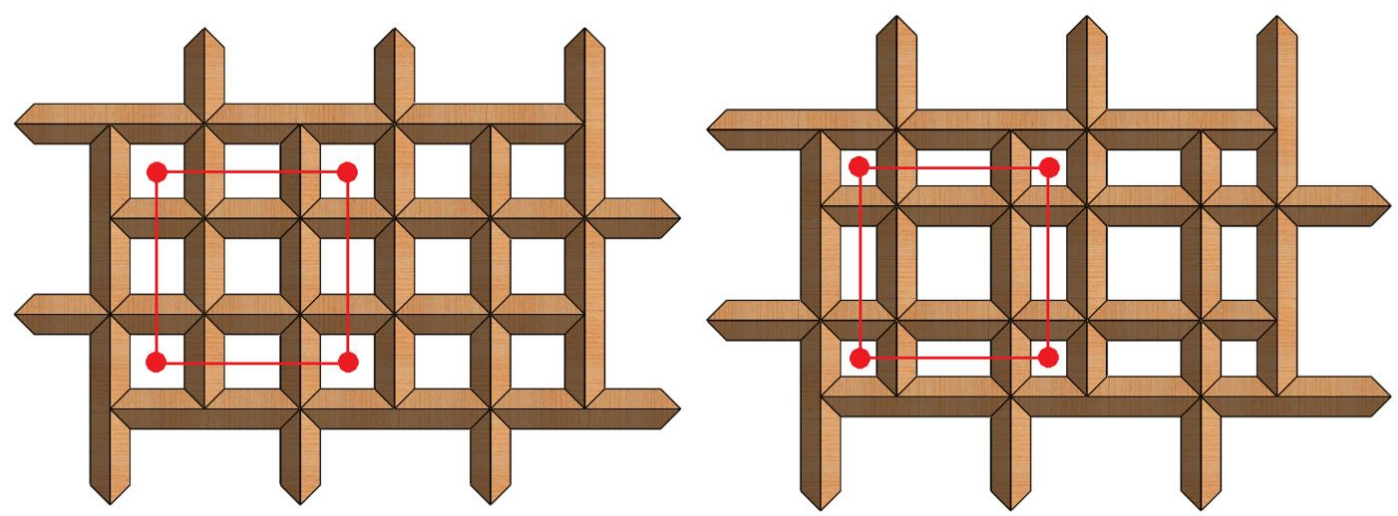

Fig. 15 Effects of the engagement length on the surface pattern

and researchers and here propose a bottom-up modelling approach, which offers an objective support for facing some of the open issues in the aesthetical development and construction of RFs.

As case studies, four temporary pavilions were analysed according to their parametric development (element morphology, fan inner arrangements, assembly, and resulting surface). We parametrically explored these RF pavilions using the proposed approach, starting to their generative elements (single element and fan) and up to developing the whole structure. In particular, we partially re-modelled each of the RFs in order to deepen their analysis and to understand (and develop) the similarity between RF growth and natural structures. The system units are linked together in order to generate a larger subsystem, and so on until the top-level system is formed. This approach is also defined as an "organic strategy", as in a natural organism that is small at the beginnings and then grows in complexity (e.g., natural honeycombs or a coral colony). The designer can play with the element parameters in order to achieve his own "living structure". It is remarkable to note how a small, local modification of a single dimension or a geometric parameter of an element (beam) causes (affects) a huge, global modification on the whole structure. This determines surprise and excitement in the observers, who can perceive the harmony of the RFs but are not always able to discern the underlying mathematical relationships. The analysed case studies represent an example of how designers may use the inner parameters of the fan element in order to determine and change the final shape of the RFs. In the analysed pavilions, these design criteria mainly consist of:

- the engagement length among the elements and the use of fan with different end dispositions (cf. Forest Park Pavilion);

- the shape of the element and its proportions (cf. the Italian Pavilion proposal for Expo 2010);

- the notch depth and the notch distances from the extremities of the element (cf. the Arched Reciprocal Frame);

- the inner angle of the V-shaped element and the inclination (cutting angle) at each element extremities (cf. WikiVault).

This offers an original point of view when compared to the traditional top-down approach, where the fan represents the lower level and it is "only" used to tessellate a surface, which is the top level. 
The structural performance of a RF mainly comes from its constructive principle, where identical (or similar) elements can be simply added and arranged in order to expand the structure. The assembly phase of a RF represents an impressive aspect of these structures: in all the references about the proposed case studies, the assembly phase is well documented by images and videos, in order to underline the strict relationship between the final aesthetic shape and the construction principle. This contributes to the inherent beauty of a RF, which, resembling a sort of perfect puzzle, can be built and expanded by simply adding new identical pieces (as in all the proposed RFs except for the WikiVault, where different elements are used in its extremities).

An important consideration emerging from this study is that a RF surface is not univocally obtained, but some combinations of values of the design parameters can lead to equal resulting surfaces. In the four case studies, for a fixed total length $L$ of the element, this may occur by:

- $\quad$ varying the engagement length and the end dispositions of the elements (cf. Forest Park Pavilion);

- changing the dimensions of the element (its total height and thickness), but keeping the value of eccentricity, or -as in the double S-shaped element of the Italian Pavilion proposal for Expo 2010 - the distance d between the horizontal surfaces;

- combining the notch depth and of the notch distances (cf. the Arched Reciprocal Frame);

- simultaneously modifying the inner angle of the V-shaped element and the inclination (cutting angle) at each element extremities (cf. WikiVault).

In order to achieve particular goals (minimum weight, small thickness, specifically shaped elements, etc.), this investigation approach may help the designer to be aware of design alternatives.

A last consideration is about the tessellation. The use of identical short beam elements constitutes an additional degree of freedom for the designer, who can create different fan arrangements in order to develop different tessellation and patterns. This strict connection between tessellation and fan arrangements in RF structures is a key point of their aesthetics. Following geometric principles, different fans can be assembled and easily modified by adding or removing identical elements: the mathematical relationships among the elements and their perfect connections - however they are assembled - is the fundament of their inherent beauty. This perception is further highlighted by the proposed bottom-up modelling approach. Among the four case studies, this is clearest in the use of the S-shaped element of the Italian Pavilion proposal for Expo 2010.

Some limitations of the proposed approach are listed as follows. The proposed method is not still completely automated and requires the designer to act manually in order to define the first fan and to complete the assembly of the structure. It can generate structures based on elongated elements, in whatever way they are shaped. When generating a structure with planar or 3D shaped elements (as in the case of the V-shaped ones), the elements need further optimization of their ends in order to achieve the best fit. 
However, the proposed approach represents a first attempt to develop a RF growth that is similar to an organic structure, like a beehive or a corallite colony, in which each cell acts both independently and referring to the other cells. As said, the key point in the development of an "aesthetical structure" is not imitating Nature but understanding its rules and therefore the mathematics of the underlying principles. The mathematics of natural forms consists of tessellation, self-similarity, spatial relationships, geometric constructions, and efficient shapes, which the designer aims to capture and further elaborate in a manmade structure.

Acknowledgments All images are by Francesco Gherardini unless otherwise noted.

\section{References}

Allen, Edward and Waclaw Zalewski. 2009. Form and Forces: Designing Efficient, Expressive Structures. Hoboken, New Jersey: John Wiley.

Baverel, Olivier and Alberto Pugnale. 2014. Reciprocal Systems Based on Planar Elements: Morphology and Design Explorations. Nexus Network Journal 16(1): 179-189.

Bryan, James and Rolf Sauer, eds. 1973. "Structures, Implicit and Explicit, Interviews with Robert Le Ricolais" In: Structures, Implicit and Explicit (VIA 2), 80-109. Philadelphia: University of Pennsylvania.

Danz, Calder. 2014. Reciprocal Frames, Nexorades and Lamellae: An Investigation into Mutually Supporting Structural Forms. University of Washington. 2014. http://dmg.be.washington.edu/reports/Reciprocal\%20Frames\%20(Danz,\%202014).pdf (accessed 20 February 2017)

Di Carlo, Biagio. 2008. The Wooden Roofs of Leonardo and New Structural Research. Nexus Network Journal 10: 27-38.

Douthe, Cyril, Olivier Baverel, and Jean-François Caron. 2006. Form-finding of a Grid Shell in Composite Materials. Journal of the International Association for Shell and Spatial Structures 47: 53-62.

Duvernoy, Sylvie. 2008. An Introduction to Leonardo's Lattices. Nexus Network Journal 10: 512.

Emmer, Michele. 2003. M.C. Escher: Art, Math, and Cinema. In: M.C. Escher's Legacy. A Centennial Celebration. Eds. Doris Schattschneider, Michele Emmer, 142-149. BerlinHeidelberg: Springer Verlag.

Fleury, François and Joël Sakarovitch. 2012. La voûte plate Abeille: analyse du comportement structurel. In: L'Architrave, le Plancher, la Plate-forme: Nouvelle Histoire de la Construction. Lausanne: Presses Polytechniques.

Gherardini, Francesco and Francesco Leali. 2016. A Framework for 3D Pattern Analysis and Reconstruction of Persian Architectural Elements. Nexus Network Journal 18(1): 133167.

Hegger, Manfred, Volker Auch-Schwelk, Matthias Fuchs, and Thorsten Rosenkranz. 2006. The Building Envelope. In: Construction Materials Manual, 103-131. Berlin: De Gruyter. 
Malek, Samar and Chris Williams. 2013. Structural Implications of Using Cairo Tiling and Hexagons in Gridshells. In: Proceedings of the International Association for Shell and Spatial Structures (IASS) Symposium 2013: Beyond the Limits of Man (September 2013, Wroclaw University of Technology, Poland). http://www2.ing.unipi.it/griff/files/1339Williams.pdf (accessed 20 February 2017).

Naicu, Dragos, Richard Harris, and Chris J.K. Williams. 2014. Timber Gridshells: Design Methods and Their Application to a Temporary Pavilion. In: World Conference on Timber Engineering, WCTE 2014 (August 2014, Quebec City, Canada).

Pizzigoni, Attilio. 2009. A High Fiber Reinforced Concrete Prototype for Reciprocal Structures of Demountable Building. In: Proceedings of the IASS Symposium 2009: Evolution and Trends in Design, Analysis and Construction of Shell and Spatial Structures (SeptemberOctober 2009 Valencia, Spain) eds. Alberto Domingo and Carlos Lazaro 1895-1906 http://hdl.handle.net/10251/7162 (accessed 20 February 2017).

Popovic Larsen, Olga. 2007. Reciprocal Frame Architecture. London: Architectural Press.

Pugnale, Alberto, Dario Parigi, Poul Henning Kirkegaard, and Mario Sassone. 2011. The Principle of Structural Reciprocity: History, Properties and Design Issues. In: Full Papers: Taller, Longer, Lighter: Meeting Growing Demand with Limited Resources: IABSE-IASS Symposium 2011. London: Hemming Group Ltd.

Pugnale, Alberto and Mario Sassone. 2014. Structural Reciprocity: Critical Overview and Promising Research/Design Issues. Nexus Network Journal 16: 9-35.

Rappaport, Nina. 2006. Deep Decoration. In: 30/60/90: Decoration, eds. Emily Abruzzo and Jonathan D. Solomon, 95-105. New York: 306090 / Princeton Architectural Press.

Robbin, Tony. 1996. Engineering: A New Architecture. New Haven: Yale University Press.

Schittich, Christian. 2006. The Surface in Contemporary Architecture. In: Construction Materials Manual, 103-131. Berlin: De Gruyter.

Sénéchal, B., Cyril Douthe, and Olivier Baverel. 2011. Analytical Investigations on Elementary Nexorades. International Journal of Space Structures 26(4): 313-320.

Song, Peng, Chi-Wing Fu, Prashant Goswami, Jianmin Zheng, Niloy J. Mitra, and Daniel CohenOr. 2013. Reciprocal Frame Structures Made Easy. In: ACM Transactions on Graphics (TOG) - SIGGRAPH 2013 Conference Proceedings (TOG), 32 (4): Article No. 94, July 2013.

Thönnissen, Udo. 2014. A Form-Finding Instrument for Reciprocal Structures. Nexus Network Journal 16: 89-107 